\title{
The influence of stony soil properties on water dynamics modeled by the HYDRUS model
}

\author{
Hana Hlaváčiková*, Viliam Novák, Zdeněk Kostka, Michal Danko, Jozef Hlavčo \\ Institute of Hydrology, Slovak Academy of Sciences, Dúbravská cesta 9, 84104 Bratislava, Slovak republic. \\ * Corresponding author. E-mail: hlavacikova@uh.savba.sk
}

\begin{abstract}
Stony soils are composed of two fractions (rock fragments and fine soil) with different hydrophysical characteristics. Although stony soils are abundant in many catchments, their properties are still not well understood. This manuscript presents an application of the simple methodology for deriving water retention properties of stony soils, taking into account a correction for the soil stoniness. Variations in the water retention of the fine soil fraction and its impact on both the soil water storage and the bottom boundary fluxes are studied as well. The deterministic water flow model HYDRUS-1D is used in the study. The results indicate that the presence of rock fragments in a moderate-to-high stony soil can decrease the soil water storage by $23 \%$ or more and affect the soil water dynamics. Simulated bottom fluxes increased or decreased faster, and their maxima during the wet period were larger in the stony soil compared to the non-stony one.
\end{abstract}

Keywords: Rock fragments; Soil water retention; Water storage; Outflow; Numerical modeling; HYDRUS-1D.

\section{INTRODUCTION}

Stony soils are composed of the fine soil fraction, i.e., small mineral particles with a diameter of less than $2 \mathrm{~mm}$, and larger rock fragments, e.g., gravel, cobbles, stones, and boulders. The size, shape, degree of weathering, geological origin, position, and a spatial distribution of rock fragments (RF) in a soil profile can strongly influence the stony soil's properties, mainly the soil's water retention and hydraulic conductivity. They can also affect soil water movement, infiltration, and the runoff formation. Although stony soils occur in many forested, mountainous, and even agricultural areas, the influence of RF on hydrological processes, water balance, and water storage are often neglected. The standardized methodology for incorporating the effects of RF on hydraulic properties and hydraulic modeling of stony soils is not available.

The research on the hydrological role of stony soils in the High Tatra Mountains began at the Institute of Hydrology of the Slovak Academy of Sciences during the international research project, which was initiated after an extraordinary windthrow in 2004. The windthrow uprooted forest in an approximately $120 \mathrm{~km}^{2}$ area and was one of ten most devastating storms in Europe over the last several decades (Gardiner et al., 2010). The international research community tried to assess the effects of such a disaster on hydrological, biogeochemical, and other processes in the affected area. Mountain soils in the High Tatra Mountains contain a lot of rock fragments. To quantify hydrological processes, it was necessary to consider the impact of RF on water flow dynamics in the soil (Novák and Kňava, 2012).

There are only a few studies that try to quantify the influence of stoniness on hydrological processes, water contents (Coppola et al., 2013), and water balance modeling (Wegehenkel et al., 2017). One of several reasons for this oversight is the sample size. Rock fragments present in stony soils are often several times larger than small mineral soil particles. Therefore, characteristics of the bulk stony soil have to be measured on an adequate representative elementary volume (REV), the size of which may be $1 \mathrm{~m}^{3}$ or larger, which is often impossible to do. According to the REV theory, a heterogeneous porous medium can be characterized by average properties of a specific volume (REV). This volume has to be large enough to average out the discontinuities of the soil structural elements (a spatial arrangement of pores and particles) but at the same time small enough compared to the entire volume of the porous medium in which the transport processes occur (Buchter et al., 1994). The appropriate REV is obtained when the porous medium property is invariant to the REV dimensions. A heterogeneous porous medium (soil) is replaced by a "hypothetically homogeneous" one, which is characterized by the effective characteristics. The effective characteristics of a stony soil characterize it as a whole and are denoted as bulk characteristics, later indicated by the subscript „b“. A standardized methodology of the estimation of REV does not yet exist. The REV of $100 \mathrm{~cm}^{3}$ (a standard sampling cylinder) has proved to be large enough for relatively homogeneous soils. Baker and Bouma (1976), Kutílek and Nielsen (1994), and Lichner (1994) recommended defining the REV of a soil as the soil sample volume, which contains no less than 20 basic elements of the soil structure (in the case of stony soils rock fragments) in the soil sample cross section. Buchter et al. (1994) recommended that the dry weight of the stony soil REV should be at least 100-times the weight of the biggest solid rock fragment. If the maximum diameter of rock fragments is about $10 \mathrm{~cm}$ and their weight about $1.5 \mathrm{~kg}$, then the minimum REV weight should be about $150 \mathrm{~kg}$.

Another difficulty in quantifying hydrological processes in stony soils arises when attempting to measure these processes. The presence of RF causes many practical problems, such as the complications that come up when inserting probes in stony soils or installing lysimeters. Moreover, field measurements encounter a large variability of stony soil characteristics even on small plots, which further complicates soil sampling and infiltration measurements. The use of tracers is difficult in stony soils as well.

An alternative way of quantifying characteristics of stony soils is to separately measure characteristics of both components (a fine soil fraction and rock fragments) and then combine them. This approach was adopted by Bouwer and Rice (1984), Brakensiek et al. (1986), Peck and Watson (1979), and Ravina and Magier (1984). Another approach is to estimate 
hydrophysical characteristics of stony soils by numerical modeling. Novák et al. (2011) were the first who used the HYDRUS-2D model in the numerical Darcy experiment. The same approach was later applied by Hlaváčiková et al. (2016) and Beckers et al. (2016). These studies examined the role of stoniness, the size of RF (Novák et al., 2011), and the shape, distribution, and position of RF in the stony soil on saturated (Hlaváčiková et al., 2016) and unsaturated hydraulic conductivities (Beckers et al., 2016).

Stony soils are usually classified according to the relative fraction of rock fragments in soil (soil stoniness) expressed as a relative volume or a relative mass. There are different systems of stony soil classifications. In this study, we applied the Morphogenetic Classification System of Slovak Soils (Societas Pedologica Slovaca, 2014). This system classifies stony soils according to a relative volume of RF as follows: slightly stony soils (with the rock fragments relative volume of 5-10 volumetric \%), moderately stony soils (with $10-25 \%$ of rock fragments), and highly stony soils (with $25-50 \%$ of rock fragments). Soils with more than $50 \%$ of rock fragments and less than $30 \%$ of organic material are classified as psefitic soils. The USDA classification allows classifying soils according to the volume of RF as: 1) nongravelly, noncobbly, nonstony soils and with less than $15 \%$ of RF, 2) gravelly, cobbly, or stony soils with $15-35 \%$ of RF, and 3) extremely gravelly, extremely cobbly, or extremely stony soils with $35-60 \%$ of RF (USDA, 2017). Rock fragments are described by their size (diameter) as gravels $(2-75 \mathrm{~mm})$, cobbles $(75-250 \mathrm{~mm})$, stones $(250-600$ $\mathrm{mm}$ ), and boulders (>600 mm) (Soil Survey Division Staff, 1993, cit. acc. to Garcia-Gaines and Frankenstein, 2015).
Stony soils represent $30 \%$ of soils in Western Europe, $60 \%$ in the Mediterranean region (Poesen and Lavee, 1994), and $43 \%$ of forest soils in Sweden (Stendahl et al., 2009). In Slovakia, Š́ly (1978) estimated that up to $80 \%$ of Slovak forest soils contain rock fragments. The systematic analysis of agricultural soils across the Slovak territory has shown that $47.2 \%$ of Slovak arable soils are classified as stony soils (VÚPOP, 2017).

The main objective of this study was to analyze the extent to which the presence of rock fragments in a stony soil can influence a) the soil water content, b) the water storage in the soil profile, and c) the bottom flux from the soil profile. The second objective was to evaluate the influence of the retention variability of the fine soil fraction on the soil water content, the water storage, and the potential bottom boundary flux. The objectives were achieved using the HYDRUS-1D model (Šimůnek et al., 2013, 2016). The soil hydraulic characteristics and the stoniness were obtained from the Červenec site, located in the Western Tatra Mts., Slovakia (Fig. 1).

\section{MATERIAL AND METHODS Study site}

The study site is located in the Jalovecký creek catchment of the Western Tatra Mountains in Slovakia. Natural conditions in the catchment are typical of the highest part of the Carpathians. The catchment covers an area of $22.2 \mathrm{~km}^{2}$. Topography is characterized by a mean slope of $30^{\circ}$ and the elevation ranges from 800 to $2178 \mathrm{~m}$ a.s.l. (the mean elevation of $1500 \mathrm{~m}$ a.s.1.). The bedrock is mostly formed by crystalline rocks and
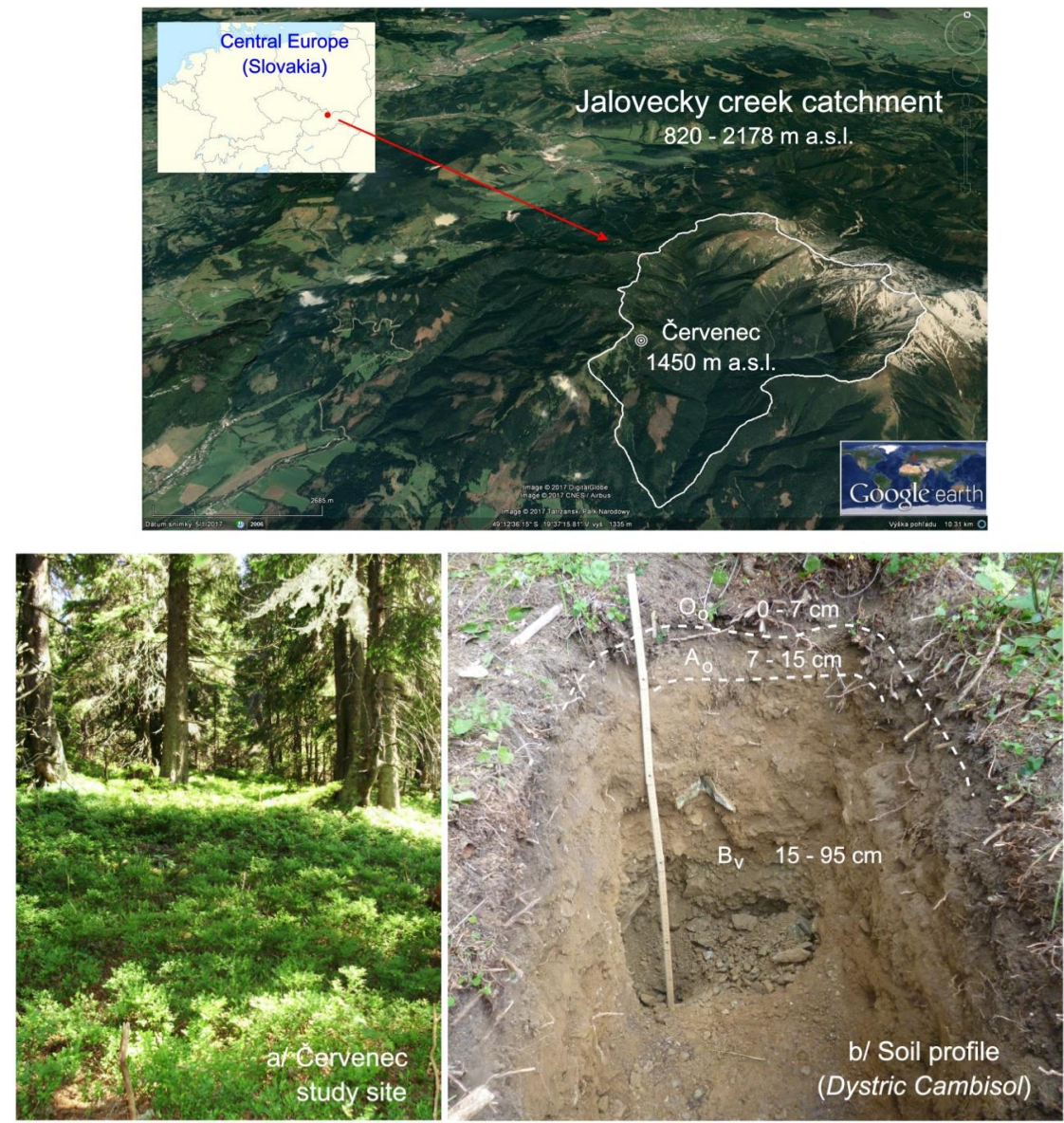

Fig. 1. Location of the study site Červenec and a typical soil profile. 
granitoides. Mesozoic rocks dominated by limestone and dolomite occur at some places. Soils are represented by Cambisol, Pozdol, Lithosol, and Leptosol. Their depth is $70-100 \mathrm{~cm}$. The stoniness of the soils is large and varies from $10-65 \%$ or more. The topsoil has a high hydraulic conductivity that surpasses the infiltration capacity several times. The Institute of Hydrology systematically has continuously monitored basic water balance components in the catchment, which is supplemented by additional experimental hydrological measurements, since the late 1980s (Holko et al., 2011; Krajčí et al., 2016).

In this study, the soil hydraulic characteristics from the site called Červenec were used for illustrative purposes (Fig. 1). This site is located at an altitude of $1450 \mathrm{~m}$ a.s.l. and has a moderately steep terrain (the slope angle is $14^{\circ}$ ). A moderateto-high stony shallow soil is typical for the site. The soil type is classified as Cambisol and has a sandy loam texture. Mean air temperature is $3.1^{\circ} \mathrm{C}$ and mean annual precipitation is 1562 $\mathrm{mm}$. A 130-year old Norway spruce forest (Picea abies) and a low crop of Vaccinium myrtillus L. grow in the area.

\section{Hydrophysical properties}

To model water flow in a stony soil, retention characteristics of the fine soil fraction, the maximum retention capacity of rock fragments, and the stoniness are needed. The stoniness was measured in the soil pit with a $1 \mathrm{~m}^{2}$ area that was $95 \mathrm{~cm}$ deep, extending down to the soil and weathered bedrock interface. Detailed information and results can be found in Hlaváčiková et al. (2015). The soil profile was divided into five layers. The uppermost layer is formed by the organic $\mathrm{O}_{0}$ horizon $(0-10 \mathrm{~cm})$. The parameters of this layer remained constant during modeling. The retention parameters of the other four layers $(10-40 \mathrm{~cm}, 40-60 \mathrm{~cm}, 60-85 \mathrm{~cm}$, and $85-95 \mathrm{~cm})$ were changed according to the stoniness of a particular soil layer. The stoniness, as it was measured in the soil pit, is presented in Table 1.

Since the measurement of the retention capacity of the stony soil would require an excessively large representative elementary volume (REV) of the sample, it was necessary to estimate the effective (bulk) retention properties of the stony soil from the separate retention characteristics of the fine soil fraction and rock fragments. The soil water retention curves (SWRC) for layers containing rock fragments were approximated from the SWRC of the fine soil fraction and measured stoniness $R_{v}$ using the modified equation of Bouwer and Rice (1984)

$$
\theta^{b}=\left(1-R_{v}\right) \theta^{f}+R_{v} \theta^{r f}
$$

where $\theta^{b}$ is the effective (bulk) volumetric water content of a stony soil $\left(\mathrm{cm}^{3} \mathrm{~cm}^{-3}\right), \theta^{f}$ is the volumetric water content of the fine soil fraction $\left(\mathrm{cm}^{3} \mathrm{~cm}^{-3}\right), R_{v}$ is the stoniness expressed as the relative volume of $\mathrm{RF}\left(\mathrm{cm}^{3} \mathrm{~cm}^{-3}\right)$, and $\theta^{r f}$ is the volumetric water content in the rock fragments. The modification of the Bouwer and Rice equation consisted of adding a term to Eq. (1) representing the retention of rock fragments. Since the rock fragments in the study site were characterized by the low maximum water capacity, a constant value of $\theta^{\text {rf }}$ (with its maximum of 5 vol. \%) was used in the model. The maximum water capacity of RF was determined by the gravimetric method using 20 samples with the size of rock fragments $2-10 \mathrm{~cm}$. The samples were dried at $105^{\circ} \mathrm{C}$, weighted, and gradually saturated for up to 7 days until their weight stabilized (Hlaváčiková et al., 2015).

Figure 2 a shows measured water retention curves of the fine soil fraction and their approximation using the van Genuchten (1980) formula. The soil water retention curves were measured on undisturbed soil samples with a volume of $100 \mathrm{~cm}^{3}$. The samples were taken in three replicates from the soil depth of $0-10 \mathrm{~cm}$, representing the forest floor horizon, and in ten replicates from the soil depth of $30-60 \mathrm{~cm}$, representing the fine mineral soil of the remaining part of the soil profile. It was not possible to take undisturbed soil samples from deeper soil depths because of the stoniness. Sampling in the depth of $10-40$ was complicated by the large density of tree roots.

Undisturbed samples taken from the soil depths of 30-60 cm did not indicate any relationship between the depth of the soil profile and the shape of the SWRC. The content of rock fragments in the samples was determined after the measurement of soil water retention curves. The average value of the soil

Table 1. The van Genuchten SWRC parameters $\left(\theta_{r}, \theta_{s}, \alpha, n\right)$, the saturated hydraulic conductivity $K_{s}$, and the soil stoniness $R_{v}$. The reference SWRC is the mean SWRC, min and max SWRCs are obtained from the mean SWRC by adding the confidence intervals for particular soil layers.

\begin{tabular}{|c|c|c|c|c|c|}
\hline \multirow[b]{2}{*}{ Soil depth $(\mathrm{cm})$} & \multirow[b]{2}{*}{$0-10 \mathrm{~cm}$} & \multicolumn{4}{|c|}{ Reference SWRC } \\
\hline & & $10-40 \mathrm{~cm}$ & $40-60 \mathrm{~cm}$ & $60-85 \mathrm{~cm}$ & $85-95 \mathrm{~cm}$ \\
\hline$\theta_{s}\left(\mathrm{~cm}^{3} \mathrm{~cm}^{-3}\right)$ & 0.600 & 0.597 & 0.487 & 0.323 & 0.241 \\
\hline \multirow[t]{2}{*}{$n(-)$} & 1.504 & 1.139 & 1.139 & 1.139 & 1.139 \\
\hline & & \multicolumn{4}{|c|}{ Min SWRC } \\
\hline Soil depth (cm) & $0-10 \mathrm{~cm}$ & $10-40 \mathrm{~cm}$ & $40-60 \mathrm{~cm}$ & $60-85 \mathrm{~cm}$ & $85-95 \mathrm{~cm}$ \\
\hline$\alpha\left(\mathrm{cm}^{-1}\right)$ & 0.043 & 0.211 & 0.211 & 0.211 & 0.211 \\
\hline \multirow[t]{2}{*}{$n(-)$} & 1.504 & 1.149 & 1.150 & 1.150 & 1.150 \\
\hline & & \multicolumn{4}{|c|}{ Max SWRC } \\
\hline Soil depth (cm) & $0-10 \mathrm{~cm}$ & $10-40 \mathrm{~cm}$ & $40-60 \mathrm{~cm}$ & $60-85 \mathrm{~cm}$ & $85-95 \mathrm{~cm}$ \\
\hline$\theta_{r}\left(\mathrm{~cm}^{3} \mathrm{~cm}^{-3}\right)$ & 0.05 & 0.05 & 0.05 & 0.05 & 0.05 \\
\hline$K_{s}\left(\mathrm{~cm} \mathrm{~h}^{-1}\right)$ & 210 & 45 & 45 & 45 & 45 \\
\hline
\end{tabular}

Values $\theta_{r}, \theta_{s}, K_{s}$ correspond to effective parameters ("bulk") in layers with RF. 

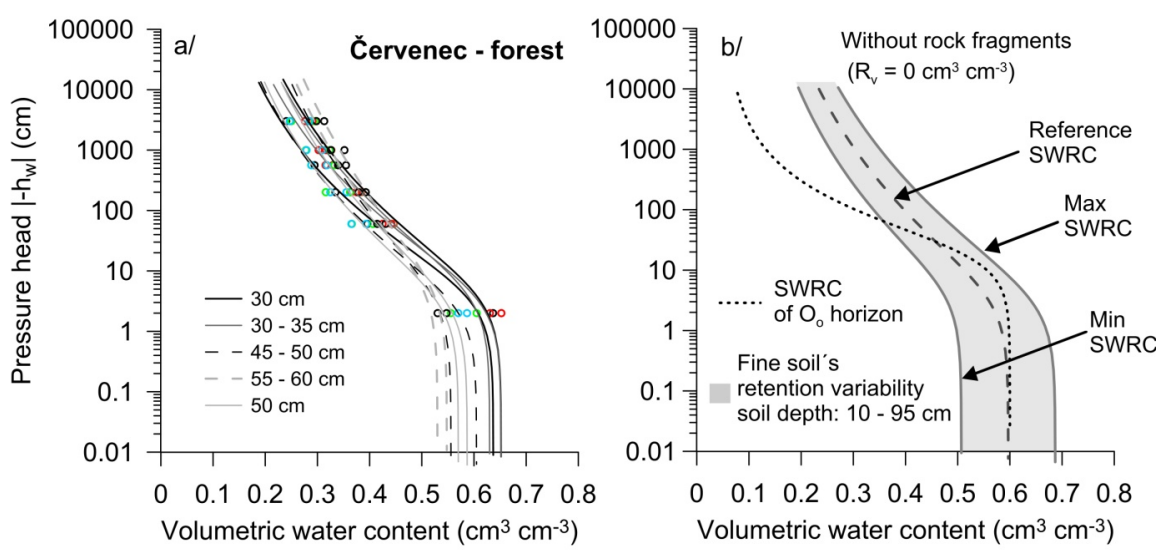

Fig. 2. a/ Measured (circles) and approximated (lines) soil water retention curves (SWRC) from the Červenec site, and b/ the SWRCs with a probability of $95 \%$ representing the soil depth of $10-95 \mathrm{~cm}$. A dashed line represents the mean (reference) SWRC of the fine soil fraction; a dotted line corresponds to the SWRC of the organic soil horizon.

sample stoniness was about $12 \%$. According to EN ISO $11274: 2014$, it is not necessary to modify retention curves of stony soils unless the stoniness exceeds $20 \%$. Therefore, undisturbed samples from the soil depth of $30-60 \mathrm{~cm}$ were used to describe water retention of the fine soil fraction. It was also assumed that the retention properties of the fine soil fraction are valid for the soil depths of $10-95 \mathrm{~cm}$ and can represent the variability of the soil for given soil depths. The variability of fine soil retention was expressed using the confidence intervals (Fig. 2b), which correspond to the mean values of the volumetric water content \pm 2 standard deviations (assuming a Gaussian probability distribution function). The mean SWRC is referred to in the remainder of this paper as the reference SWRC for $R_{v}=0 \mathrm{~cm}^{3} \mathrm{~cm}^{-3}$. The confidence intervals are denoted as min or $\max \mathrm{SWRC}$ for $R_{v}=0 \mathrm{~cm}^{3} \mathrm{~cm}^{-3}$.

The process of preparation and estimation of retention properties of the fine soil fraction of stony soils can alternatively include the possibility of preparing disturbed soil samples (a fine soil fraction only, i.e., sieved particles with a diameter smaller than $2 \mathrm{~mm}$ ). This methodology is appropriate when it is not possible to take undisturbed soil samples. However, the structure, and consequently retention properties of these samples, will differ from undisturbed samples and they will closely depend on the method of their preparation.

Figure 3 shows all SWRC used in modeling. The SWRC (the reference function and its confidence intervals) for soil layers containing rock fragments (below a depth of $40 \mathrm{~cm}$ ) were derived using Eq. (1). They were expressed as the reference SWRC (derived from the mean reference SWRC for $R_{v}=0$ $\mathrm{cm}^{3} \mathrm{~cm}^{-3}$ ) and the confidence intervals (min, max) were derived from the SWRC confidence intervals (min, max SWRC for $R_{v}=0 \mathrm{~cm}^{3} \mathrm{~cm}^{-3}$ ). Parameters of all soil water retention curves (either reference or confidence intervals) for particular soil depths are in Table 1. Figure 3 shows how the retention of the soil profile decreases with increasing stoniness. The stoniness at soil depths of $40-60 \mathrm{~cm}$ was $0.2 \mathrm{~cm}^{3} \mathrm{~cm}^{-3}$, while at depths of $60-85 \mathrm{~cm}$ it was $0.5 \mathrm{~cm}^{3} \mathrm{~cm}^{-3}$. The presence of stones in deeper soil layers caused a reduction of the retention capacity of particular soil layers by almost one half.

Two scenarios were considered in the modeling study. Scenario 1 represented a non-stony soil, while scenario 2 represented a stony soil. Hydraulic conductivities for the two scenarios were the same. The saturated hydraulic conductivities of the $0-10 \mathrm{~cm}$ and $10-95 \mathrm{~cm}$ soil layers were set to mean measured values of $210 \mathrm{~cm} \mathrm{~h}^{-1}$, and $45 \mathrm{~cm} \mathrm{~h}^{-1}$, respectively.

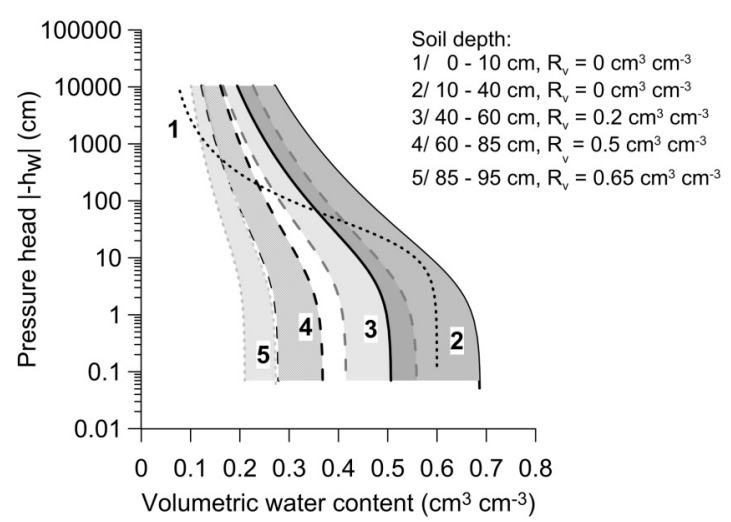

Fig. 3. The soil water retention curve for the organic soil horizon $(0-10 \mathrm{~cm})(1)$ and for deeper soil horizons $(2-5)$ corrected according to the soil stoniness $R_{v}\left(\mathrm{~cm}^{3} \mathrm{~cm}^{-3}\right)$. Shaded areas represent the fine soil water retention variability of a particular soil depth interval.

The saturated hydraulic conductivities were estimated using single ring infiltration measurements and laboratory measurements (Hlaváčiková et al., 2014). The forest floor soil horizon typically has a large infiltration capacity which decreases with the soil depth and the increase in the rock fragments content. This trend has been confirmed using infiltration measurements in several soil profiles at different sites in the catchment (not shown here). As this study focuses primarily on the reduced retention capacity of the stony soil caused by stoniness and its influence on the soil water content and the bottom boundary outflow, hydraulic conductivities remained constant across different stoninesses.

The first set of modeling runs was performed for the 2013 vegetation season (June to September). The model was run using daily values of meteorological data collected at the nearby meteorological station. Throughfall was measured directly at the experimental site. Phenological parameters of the crop present at the site, representing Vaccinium myrtillus L., were set as follows: LAI (leaf area index) was $1.07 \mathrm{~cm}^{2} \mathrm{~cm}^{-2}$, the crop height was $30 \mathrm{~cm}$, the root depth was $30 \mathrm{~cm}$, and albedo was $0.2(-)$. LAI was set according to the direct measurement of one-sided leaf area of Vaccinium myrtillus for a unit soil surface area $\left(1 \mathrm{~m}^{2}\right)$. The second set of modeling runs was carried out using 1-minute time steps for the short, extreme rainfall event, which occurred on 14-16 May 2014. Transpiration and evaporation fluxes were neglected in this second scenario. 
The bottom boundary condition specified at a depth of 95 $\mathrm{cm}$ was a free drainage. This condition was chosen because the rate of water flow on the soil-weathered bedrock interface was not known. It was assumed that all water, which flows through the bottom boundary of the soil, contributes to the formation of subsurface outflow. Simulated soil water contents were compared with measured values to verify that simulated results did not contradict the reality. Soil water contents were measured using the Delta-T devices. A limited set of manual measurements using the Wet-2 sensor was available for a soil depth of $0-10 \mathrm{~cm}$. Continuous measurements by the SM300 sensor were carried out at the soil depth of $40 \mathrm{~cm}$. Finally, the water balance error was checked for both types of modeling runs.

Several assumptions and simplifications were considered for water flow modeling. It was assumed that water flow could be described by the Richards equation in the unsaturated zone of the soil profile and that water flowed only through the soil matrix and preferential flow could be neglected. The single porosity HYDRUS-1D model (ver. 4.17) was used (Šimůnek et al., 2013).

Modeled soil water contents, water storage, and bottom boundary outflows for the stony soil were compared with modeled values for the non-stony soil using the root mean square error (RMSE) and the mean relative error (MRE in \%).

\section{RESULTS AND DISCUSSION}

The stoniness of the soil profile at the study site Červenec increased with the soil depth. It varied according to soil layers from $0.2 \mathrm{~cm}^{3} \mathrm{~cm}^{-3}$ in the soil depth of $40-60 \mathrm{~cm}$ to $0.65 \mathrm{~cm}^{3} \mathrm{~cm}^{-3}$ in $85-95 \mathrm{~cm}$. The overall average stoniness of the soil profile was $0.28 \mathrm{~cm}^{3} \mathrm{~cm}^{-3}$. According to Morphogenetic Classification System of Slovak Soils (Societas Pedologica Slovaca, 2014), the soil can be classified as a highly stony soil. The modeling results indicated that the presence of rock fragments caused a substantial reduction in the retention capacity of the soil profile, especially below the soil depth of $60 \mathrm{~cm}$. The simulated and measured volumetric water contents as a function of time in different depths are shown in Figure 4.

The presence of rock fragments in the studied soil profile caused the volumetric water content to decrease on average by $0.06,0.16$, and $0.2 \mathrm{~cm}^{3} \mathrm{~cm}^{-3}$ in the soil depths of 55, 75, and 90 $\mathrm{cm}$, respectively (Fig. 4, thicker dashed lines). These values corresponded to a relative decrease by $18-56 \%$. Consequently, the total soil water storage (for the entire stony soil profile) decreased by $7.6 \mathrm{~cm}(23 \%)$. It is worth mentioning that the vegetation growing at the site, namely Norway spruce Picea abies, which was not considered in the modeling, is generally characterized as a primary "surface rooter". While this fact was not confirmed in some studies (e.g., Puhe, 2003), most of the root mass is usually not deeper than $40 \mathrm{~cm}$, which can be partially explained by the stoniness of the soil.

The flux at the bottom soil boundary increased or decreased faster in the stony soil than in the non-stony soil, especially during wet periods (Fig. 5). Maximum bottom flux values were larger in the stony soil as well. On the other hand, the simulated bottom flux during the dry period was smaller in the stony soil than in the non-stony soil. This was caused mainly by the smaller water retention of the stony soil. However, cumulative fluxes for the entire vegetative period were not very different for the two soils. Simulated outflows were 161 and $148 \mathrm{~mm}$ for the stony and non-stony soils, respectively, which correspond to $38 \%$ and $41 \%$ of infiltration. It can be expected that these differences throughout the hydrological year will be minimal.

The difference between water dynamics in the stony and non-stony soils was significant, particularly in the short time periods. Water flow was therefore simulated for one real rainfall event (Fig. 6). The outflow from the stony soil was $18 \%$ larger than from the non-stony soil during this rainfall event. The outflow coefficients were $69 \%$ and $58 \%$ for the stony and the non-stony soil, respectively.

With respect to the retention variability of the fine soil fraction, its effect decreased with an increase in the stoniness as expected (Fig. 4, shaded area). The retention variability of the fine soil fraction produced a change in the volumetric water content in the entire soil profile (soil depths of 10-90 cm, not shown here). The largest variability in the range of \pm 0.06 $\mathrm{cm}^{3} \mathrm{~cm}^{-3}$ compared to the reference volumetric water content was in the soil depths with minimum stoniness $(10-40 \mathrm{~cm})$. For example, at a depth of $90 \mathrm{~cm}$, this variability was only about $\pm 0.02 \mathrm{~cm}^{3} \mathrm{~cm}^{-3}$ (Fig. 4).

As discussed earlier, it is not easy to estimate effective (bulk) hydrophysical properties of stony soils. The methods used to prepare the samples with the fine soil fraction of stony soils and how their retention characteristics are consequently estimated will affect modeling results. The retention properties of the fine soil fraction can be derived either from undisturbed soil samples (in a case of a small stoniness) or from disturbed samples (in a case of a highly stony soil). It is not known how much the retention properties of the fine soil fraction derived using these two approaches affect modeling results. However, according to our experience, it can be expected that the influence of different methods of estimating retention properties of the soil fine fraction on modeled water contents will decrease with increasing soil stoniness.

The retention variability of the fine soil fraction changed the total soil water storage of the entire soil profile in the range of $\pm 5.2 \mathrm{~cm}( \pm 15 \%)$ in the non-stony soil. The corresponding change in the stony soil was $\pm 3.8 \mathrm{~cm}$, a decrease of $11.5-34 \%$. The effect of the retention variability of the fine soil fraction on cumulative outflow in the non-stony and stony soils varied in the range of $13.9-15.8 \mathrm{~cm}( \pm 6.7 \%)$ and $15.3-17 \mathrm{~cm}$ (an increase by $3.3-14.8 \%$ ), respectively.

Tables 2 and 3 show components of the water balance equation for the vegetative period and for an extreme rainfall event, respectively. The water storage at the beginning and the end of the simulated period are shown as well.

Properties of stony soils are a result of mutual interaction among factors in a complex soil system. Modeling of water flow in stony soils requires several simplifications and approximations, such as the assumption of laminar water flow expressed by the Richards equation or in the case of this study, neglecting of preferential flow (PF). The presence of PF is certainly a very important phenomenon, especially in forest and mountain soils. In the case of stony soils, a special type of macropores, called lacunar pores, can occur at the interface of rock fragments and the fine soil fraction. However, the parameters describing these processes, such as the fraction of water flow transported by preferential pathways in the stony soil or the rate of the water flow exchange between slower and faster flow areas in the stony soil, were not available. This is a great challenge for further research. However, it should be emphasized that the goal of this study was to estimate the influence of the reduced retention capacity of stony soils by the presence of RF on the soil water dynamics. Preferential pathways are not only caused by the presence of rock fragments, but also by different biological, geochemical, and hydrological processes taking place in soils. PF together with the presence of rock fragments in stony soils affects the water storage and, consequently, soil water dynamics. 


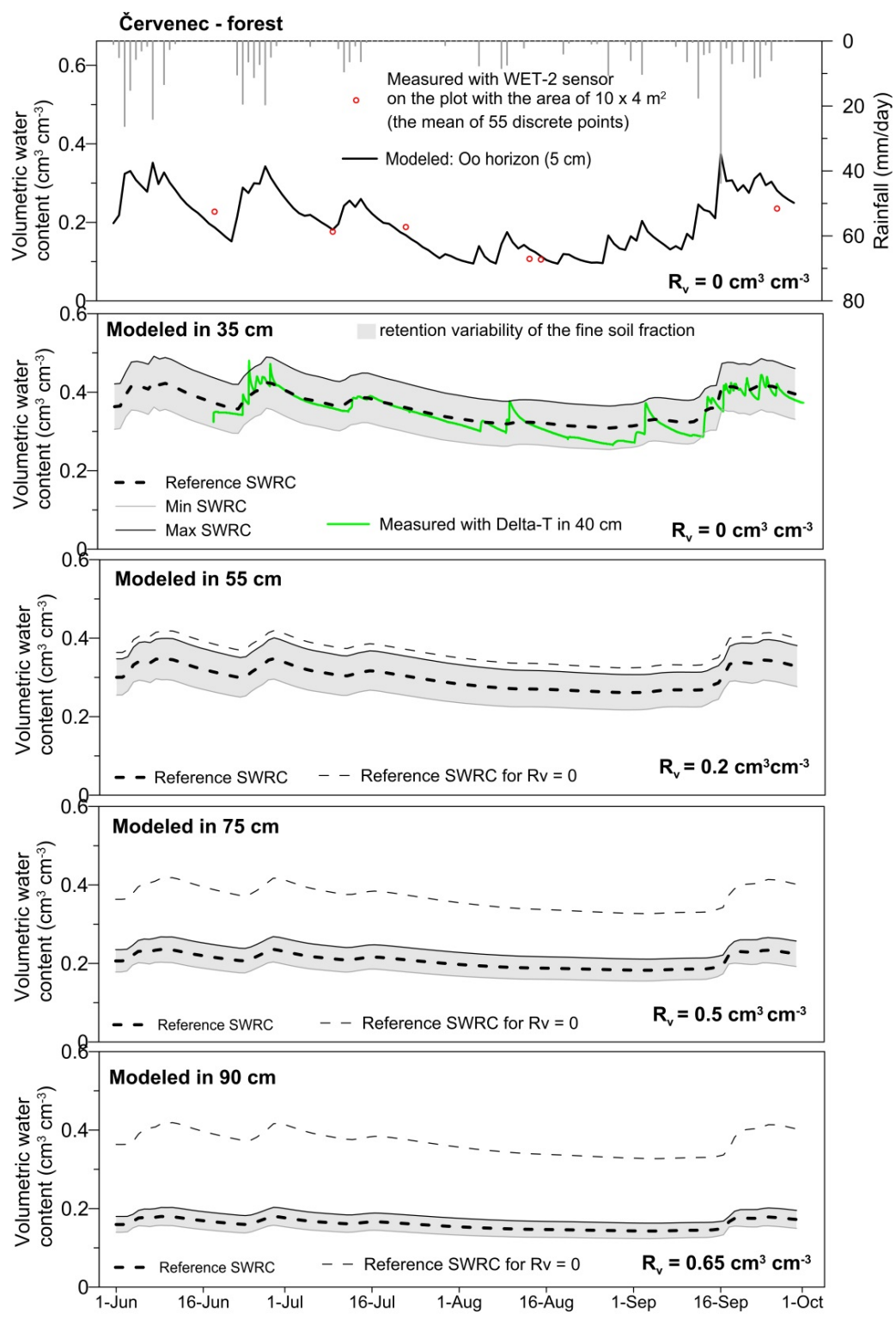

Fig. 4. Precipitation (top), and measured and simulated volumetric water contents in the stony soil profile. Simulations considered the variability of the fine soil water retention (shaded area). The reference SWRC for $R_{v}=0$ denotes to the mean SWRC used in the scenario of a non-stony soil (without rock fragments). The reference SWRC for the stony soil $\left(R_{v}>0\right)$ denotes the mean SWRC modified by the stoniness. It indicates the differences in modeled water contents caused by the stoniness (increasing with the soil depth).

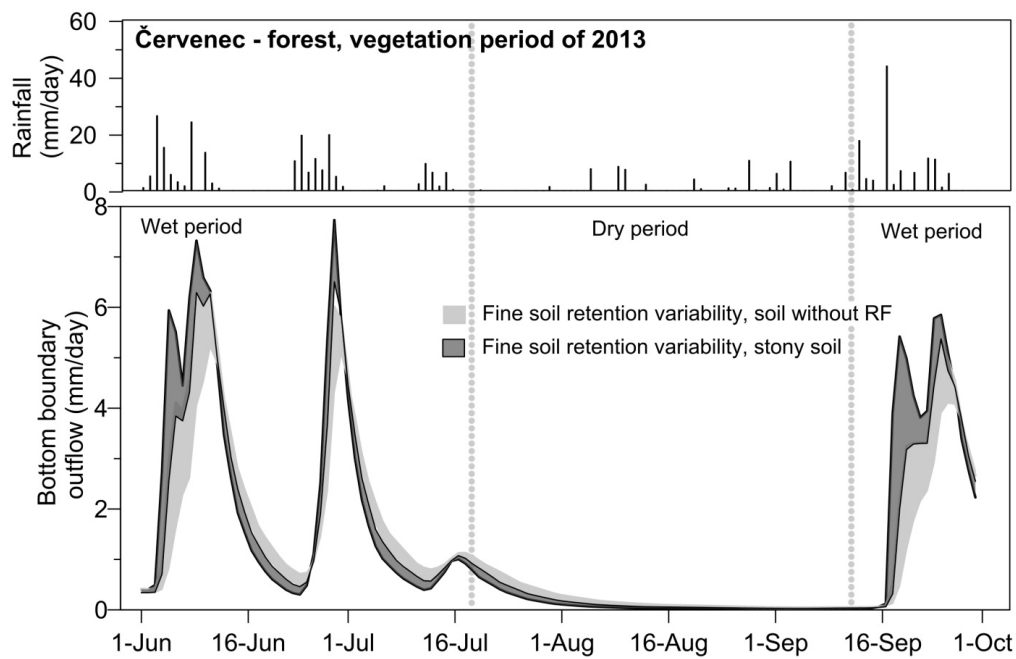

Fig. 5. Precipitation (top) and bottom boundary outflow (at a depth of $95 \mathrm{~cm}$ ) from the non-stony and stony soil profile. Simulations considered the variability of the fine soil water retention. 
The influence of stony soil properties on water dynamics modeled by the HYDRUS model

Table 2. Components of the soil profile water balance and water storage at the beginning and the end of the simulated vegetative period. Surface runoff did not occur.

\begin{tabular}{|c|c|c|c|c|c|c|c|c|}
\hline 01.06. - 30.9.2013 & $\begin{array}{c}\text { Cumulative } \\
\text { infiltration } \\
(\mathrm{mm})\end{array}$ & $\begin{array}{c}\text { Cumulative } \\
\text { evaporation } \\
(\mathrm{mm})\end{array}$ & $\begin{array}{c}\text { Cumulative } \\
\text { transpiration } \\
(\mathrm{mm})\end{array}$ & $\begin{array}{l}\text { Cumulative } \\
\text { bottom } \\
\text { boundary } \\
\text { outflow } \\
(\mathrm{mm})\end{array}$ & $\begin{array}{l}\text { Outflow as a } \\
\text { percentage of } \\
\text { infiltration } \\
(\%)\end{array}$ & $\begin{array}{c}\text { Initial } \\
\text { water } \\
\text { storage } \\
(01.06) \\
(\mathrm{mm}) \\
\end{array}$ & $\begin{array}{c}\text { Final water } \\
\text { storage } \\
(30.09 .) \\
(\mathrm{mm})\end{array}$ & $\begin{array}{c}\text { Absolute } \\
\text { water } \\
\text { balance } \\
\text { error } \\
(\mathrm{mm})\end{array}$ \\
\hline Non-stony soil, Reference SWRC & 380 & 127 & 74 & 148 & 37.9 & 328.4 & 363.6 & 4 \\
\hline Non-stony soil, Min SWRC & 380 & 124 & 74 & 158 & 40.5 & 279.5 & 308.0 & 3 \\
\hline Non-stony soil, Max SWRC & 380 & 129 & 75 & 139 & 35.7 & 377.6 & 418.6 & 4 \\
\hline Stony soil, Min SWRC & 380 & 120 & 73 & 170 & 43.6 & 220.8 & 241.2 & 3 \\
\hline Stony soil, Max SWRC & 380 & 126 & 74 & 153 & 39.3 & 292.3 & 322.7 & 4 \\
\hline
\end{tabular}

Table 3. Components of the soil profile water balance and water storage at the beginning and the end of the rainfall period, and 7 days after the rainfall onset. Cumulative surface runoff with a value of $0.3 \mathrm{~mm}$ was neglected.

\begin{tabular}{lccccc}
\hline May 14-16, 2015 & $\begin{array}{c}\text { Cumulative } \\
\text { infiltration } \\
(\mathrm{mm})\end{array}$ & $\begin{array}{c}\text { Cumulative bottom } \\
\text { boundary outflow } \\
(\mathrm{mm})\end{array}$ & $\begin{array}{c}\text { Initial water storage (at } \\
\text { the rainfall onset) } \\
(\mathrm{mm})\end{array}$ & $\begin{array}{c}\text { Final water } \\
\text { storage* } \\
(\mathrm{mm})\end{array}$ & $\begin{array}{c}\text { Absolute water } \\
\text { balance error } \\
(\mathrm{mm})\end{array}$ \\
\hline Non-stony soil, Reference SWRC & & & & & \\
*/ at the end of rainfall (16 May) & 234 & 74 & 282 & 441 & 1 \\
*/7 days after rainfall onset (21 May) & 234 & 138 & 282 & 377 & 1 \\
\hline Stony soil, Reference SWRC & & & & & \\
*/ at the end of rainfall (16 May) & 234 & 111 & 221 & 344 & 0 \\
*/7 days after rainfall onset (21 May) & 234 & 163 & 221 & 291 & 1 \\
\hline
\end{tabular}

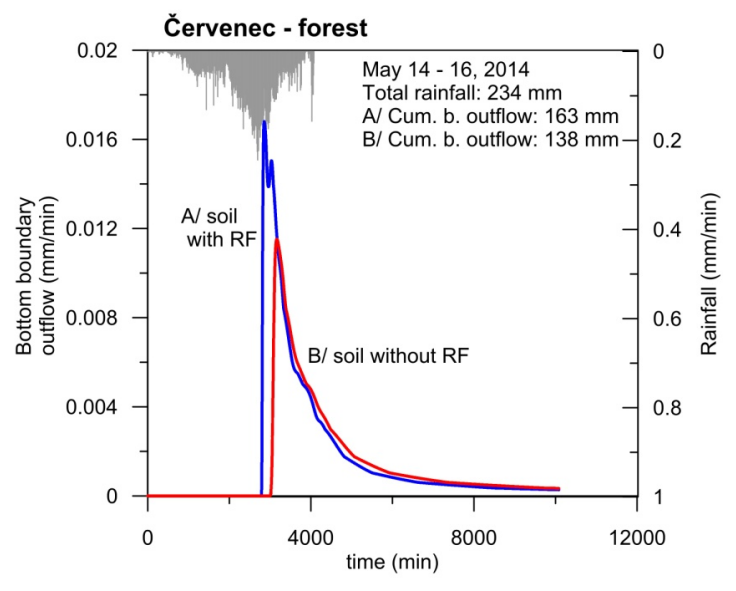

Fig. 6. Extreme rainfall and the bottom boundary flux (at a depth of $95 \mathrm{~cm}$ ) of the non-stony and stony soil profile.

\section{CONCLUSIONS}

The presence of rock fragments in stony soils complicates the measurement of the hydrophysical characteristics of stony soils, which are needed for water flow modeling. The direct measurement of the soil moisture dynamics in stony soils is problematic as well. It may even be impossible in the case of a large stoniness considering the problems with the installation of measurement devices on one hand and the interpretation of measured values on the other. Therefore, using a suitable model as a tool for estimating water dynamics in a stony soil seems to be a promising approach to overcoming these problems.

A simple methodology was used in this study to estimate the effects of rock fragments on the water dynamics in the stony soils and the corresponding soil water storage by water flow modeling. The results of modeling showed that:
1, Neglecting the presence of stones in modeling of water flow in the moderately or highly stony soils can result in a substantial overestimation of the soil water storage.

2 , Rock fragments reduce the volume of the soil that is available for water flow and thus speed-up the water dynamics in the stony soils, especially during the short wet periods. Numerical modeling showed that outflow from the stony soils following rainfall is characterized by higher maxima and lower minima compared to the non-stony soils. The stoniness can contribute to the extreme outflows from the catchment.

The response of the stony soils to the rainfall events compared with the response of non-stony soils depends on a number of mutually influencing factors such as the rainfall intensity and duration, the initial soil water content, and the soil profile depth. The stony soil properties, such as the amount, size, and distribution of rock fragments in the soil profile, the retention of rock fragments, the fine soil fraction properties (retention and hydraulic conductivity), the presence of active preferential flow paths, and the bedrock properties can strongly influence outflow formation. The terrain and the bedrock slope will contribute to the soil's response to rainfall events by lateral outflow, especially in the case of less permeable bedrock.

Further research of structured stony soils and the verification of the proposed methodology are highly recommended, as the effects of rock fragments on the hydrological cycle of forested or agricultural stony soils is still often neglected.

Acknowledgement. This contribution was supported by the grant agency of the Slovak Academy of Sciences VEGA, project No. 2/0055/15 and is the result of the project implementation ITMS 26240120004 Centre of excellence for integrated flood protection of land supported by the Research \& Development Operational Program funded by the ERDF. Some equipment that provided data for this study was obtained within the framework of European Regional Development Fund Project 26220120062 'Centre of excellence for the integrated river basin management in changing environmental conditions'. 


\section{REFERENCES}

Baker, F.G., Bouma, J., 1976. Variability of hydraulic conductivity in two subsurface horizons of two silt loam soils. Soil Sci. Soc. Am. J., 40, 219-222.

Beckers, E., Pichault, M., Pansak, W., Degré, A., Garré, S., 2016. Characterization of stony soil'hydraulic conductivity using laboratory and numerical experiments. Soil, 2, 421431.

Bouwer, H., Rice, R.C., 1984. Hydraulic Properties of Stony Vadose Zones. Ground Water, 22, 696-705.

Brakensiek, D.L., Rawls, W.J., Stephenson, G.R., 1986. Determining the saturated hydraulic conductivity of a soil containing rock fragments. Soil Sci. Soc. Am. J., 50, 834-835.

Buchter, B., Hinz, C., Flühler, H., 1994. Sample size for determination of coarse fragment content in a stony soil. Geoderma, 63, 265-275.

Coppola, A., Dragonetti, G., Comegna, A., Lamaddalena, N., Caushi, B., Haikal, M.A., Basile, A., 2013. Measuring and modeling water content in stony soils. Soil \& Tillage Research, 128, 9-22.

EN ISO 11274:2014. Soil quality - Determination of the waterretention characteristic - Laboratory methods (ISO 11274:1998+Cor. 1:2009). European Committee for Standardization, CEN-CENELEC Management Centre, Brussels.

Garcia-Gaines, R.A., Frankenstein, S., 2015. USCS and the USDA Soil Classification System: Development of a Mapping Scheme. U.S. Army Engineer Research and Development Center, Vicksburg, $46 \mathrm{p}$.

Gardiner, B., Blennow, K., Carnus, J., Fleischer, P., Ingemarson, F., Landmann, G., Lindner, M., Marzano, M., Nicoll, B., Orazio, C., Peyron, J.L., Reviron, M.P., Schelhaas, M., Schuck, A., Spielmann, M., Usbeck, T., 2010. Destructive Storms in European Forests: Past and Forthcoming Impacts. Final Report to European Commission. - DG Environment. European Forest Institute, Joensuu, Finland, 138 p.

Hlaváčiková, H., Novák, V., Orfánus, T., Danko, M., Hlavčo, J., 2014. Stony soil hydrophysical characteristics. I. Hydraulic conductivities. Acta Hydrologica Slovaca, 15, 24 34. (In Slovak with English abstract and summary.)

Hlaváčiková, H., Novák, V., Holko, L., 2015. On the role of rock fragments and initial soil water content in the potential subsurface runoff formation. J. Hydrol. Hydromech., 63, 7191.

Hlaváčiková, H., Novák, V., Šimůnek, J., 2016. The effects of rock fragment shapes and positions on modeled hydraulic conductivities of stony soils. Geoderma, 281, 39-48.

Holko, L., Kostka, Z., Šanda, M., 2011. Assessment of frequency and areal extent of overland flow generation in a forested mountain catchment. Soil \& Water Res., 6, 43-53.

Krajčí, P., Danko, M., Hlavčo, J., Kostka, Z., Holko, L., 2016. Experimental measurements for improved understanding and simulation of snowmelt events in the Western Tatra Mountains. J. Hydrol. Hydromech., 64, 316-328.

Kutílek, M., Nielsen, D.R., 1994. Soil Hydrology. Cremlingen - Destedt, Catena Verlag, 370 p.
Lichner, L., 1994. Contribution to the saturated hydraulic conductivity of soils with macropores measurement. J. Hydrol. Hydromech., 42, 421-430. (In Slovak with English abstract.)

Novák, V., Kňava, K., 2012. The influence of stoniness and canopy properties on soil water content distribution: simulation of water movement in forest stony soil. Eur. J. Forest Res., 131, 1727-1735.

Novák, V., Kňava, K., Šimůnek, J., 2011. Determining the influence of stones on hydraulic conductivity of saturated soils using numerical method. Geoderma, 161, 177-181.

Peck, A.J., Watson, J.D., 1979. Hydraulic conductivity and flow in non-uniform soil. In: Proc. Workshop on soil physics and soil heterogeneity, CSIRO Division of Environmental Mechanics, Canberra, Australia.

Poesen, J., Lavee, H., 1994. Rock fragments in top soils: significance and processes. Catena, 23, 1-28.

Puhe, J., 2003. Growth and development of the root system of Norway spruce (Picea abies) in forest stands - a review. Forest Ecology and Management, 175, 253-273.

Ravina, I., Magier, J., 1984. Hydraulic conductivity and water retention of clay soils containing coarse fragments. Soil Sci. Soc. Am. J., 48, 736-740.

Šály, R., 1978. Soil - Basic Component of Forest Production. Príroda Publ. House, Bratislava. (In Slovak.)

Šimůnek, J., Šejna, M., Saito, H., Sakai, M., van Genuchten, M.T., 2013. The HYDRUS-1D Software Package for Simulating the One-Dimensional Movement of Water, Heat, and Multiple Solutes in Variably-Saturated Media, Version 4.17. Department of Environmental Sciences, University of California Riverside, Riverside, CA, USA, 308 p.

Šimůnek, J., van Genuchten, M.T., Šejna, M., 2016. Recent developments and applications of the HYDRUS computer software packages. Vadose Zone J., 15, 7. DOI: 10.2136/vzj2016.04.0033.

Societas Pedologica Slovaca, 2014. Morphogenetic Classification System of Slovak Soils. Basal Reference Taxonomy. 2nd revised edition Bratislava: NPPC-VÚPOP Bratislava, 96 p. (In Slovak with English abstract.)

Stendahl, J., Lundin, L., Nilsson, T., 2009. The stone and boulder content of Swedish forest soils. Catena, 77, 285291.

USDA, 2017. Determination of grain size distribution. http://www.nrcs.usda.gov/wps/portal/nrcs/detail/soils/survey /office/ssr10/tr/?cid=nrcs144p2_074845\#item1b. Accessed 20 June 2017.

van Genuchten, M.T., 1980. A closed-form equation for predicting the hydraulic conductivity of unsaturated soils. Soil Sci. Soc. Am. J., 44, 987-996.

VÚPOP, 2017. Representation of stoniness categories in Slovak agricultural soils. http:// www. podnemapy. sk/portal/ reg_pod infoservis/skelet/skelet.aspx. (In Slovak.)

Wegehenkel, M., Wagner, A., Amoriello, T., Fleck, S., Messenburg, H., 2017. Impact of stoniness correction of soil hydraulic parameters on water balance simulations of forest plots. J. Plant Nutr. Soil Sci., 180, 71-86.

Note: Colour version of Figures can be found in the web version of this article. 